\title{
Neoantigen vaccine: an emerging tumor immunotherapy
}

\author{
Miao Peng ${ }^{1,2,3}$, Yongzhen $\mathrm{Mo}^{2}$, Yian Wang ${ }^{2}$, Pan Wu ${ }^{2}$, Yijie Zhang ${ }^{2}$, Fang Xiong ${ }^{2}$, Can Guo ${ }^{2}$ Xu Wu ${ }^{1,2}$, Yong Li ${ }^{4}$, \\ Xiaoling Li ${ }^{2}$, Guiyuan $\mathrm{Li}^{1,2,3}$, Wei Xiong ${ }^{1,2,3}$ and Zhaoyang Zeng ${ }^{1,2,3^{*}}$
}

\begin{abstract}
Genetic instability of tumor cells often leads to the occurrence of a large number of mutations, and expression of non-synonymous mutations can produce tumor-specific antigens called neoantigens. Neoantigens are highly immunogenic as they are not expressed in normal tissues. They can activate CD4+ and CD8+ T cells to generate immune response and have the potential to become new targets of tumor immunotherapy. The development of bioinformatics technology has accelerated the identification of neoantigens. The combination of different algorithms to identify and predict the affinity of neoantigens to major histocompatibility complexes (MHCs) or the immunogenicity of neoantigens is mainly based on the whole-exome sequencing technology. Tumor vaccines targeting neoantigens mainly include nucleic acid, dendritic cell (DC)-based, tumor cell, and synthetic long peptide (SLP) vaccines. The combination with immune checkpoint inhibition therapy or radiotherapy and chemotherapy might achieve better therapeutic effects. Currently, several clinical trials have demonstrated the safety and efficacy of these vaccines. Further development of sequencing technologies and bioinformatics algorithms, as well as an improvement in our understanding of the mechanisms underlying tumor development, will expand the application of neoantigen vaccines in the future.
\end{abstract}

Keywords: Neoantigen, Tumor, Vaccine, Malignancy, Immunotherapy

\section{Introduction}

Malignant tumors are associated with high morbidity and mortality worldwide. According to the latest statistics released by GLOBOCAN, there were 18.1 million new cases of cancer and 9.6 million cancer-related deaths in 2018 [1]. Thus, malignant tumors constitute a considerable threat to human health $[2,3]$.

The traditional treatment for malignant tumors is based on surgery, radiotherapy, chemotherapy, and targeted treatment, each with its pros and cons. Surgery cannot always completely remove tumor cells, and recent studies suggest that reaction to post-operative wound healing may lead to the growth of metastatic

\footnotetext{
* Correspondence: zengzhaoyang@csu.edu.cn

${ }^{1} \mathrm{NHC}$ Key Laboratory of Carcinogenesis and Hunan Key Laboratory of Translational Radiation Oncology, Hunan Cancer Hospital and The Affiliated Cancer Hospital of Xiangya School of Medicine, Central South University, Changsha, Hunan, China

${ }^{2}$ Key Laboratory of Carcinogenesis and Cancer Invasion of the Chinese Ministry of Education, Cancer Research Institute, Central South University, Changsha, Hunan, China

Full list of author information is available at the end of the article
}

tumors [4]. Radiotherapy and chemotherapy tend to elicit tolerance and recurrence of tumor cells, resulting in poor prognosis [5-8]. Specificity is the advantage of using targeted therapy. Early clinical trials on multiple tumor types have shown that single-molecule targeted therapy has a higher response rate and survival rate than other therapies [9-11], although problems such as unsatisfactory drug development and high cost persist [12].

In recent years, tumor immunotherapy has emerged as a new approach for eliminating malignant tumors. Checkpoints on the surface of $\mathrm{T}$ lymphocytes act as molecular brakes during immune response to maintain the balance of the immune system. Researchers have shown that tumor cells can express checkpoint inhibitors to achieve immune escape [13]. Allison and Honjo, winners of the Nobel Prize in physiology and medicine in 2018, showed that cytotoxic T lymphocyte antigen 4 (CTLA-4) and programmed cell death protein 1 (PD-1) act as negative immune regulatory factors and inhibit anti-tumor immune response. They also confirmed that antibody-mediated blockage of immune checkpoints 
removes the inhibition of immune cells by tumor cells and achieves anti-tumor effect [14-20], which forms the basis of the immune checkpoint inhibition therapy. Clinical trials have shown that immune checkpoint regulation therapy has good potential, although the effect is limited in many cases, especially in solid tumors where the response rate is low. Another popular immunotherapy is adoptive T-cell therapy, which is a type of passive immunotherapy. This method involves activation and amplification of the patient's autologous $\mathrm{T}$ lymphocytes in vitro and then returning them to the body to kill tumor cells [21]. Currently, remarkable results have been achieved in clinical trials, although the effect on solid tumors is limited [22, 23]. However, adoptive $\mathrm{T}$ cells have poor in vivo persistence, cytotoxicity, and other defects $[24,25]$, and may trigger inflammatory factor storms.

In addition to immune system suppression, the weak immunogenicity of tumor cells is another reason underlying their immune escape. Therefore, the search for neoantigens with stronger immunogenicity has become a key issue in immunotherapy. Currently, sequencing technology and bioinformatics algorithm have made considerable progress, and researchers have clarified the role of major MHC proteins in antigen presentation [26, 27], realized the proliferation of antigen-specific $\mathrm{T}$ lymphocytes in vitro [28, 29], and cloned and expressed genes using molecular biological techniques. These advancements provide the necessary support for molecular identification of neoantigens. The presence of neoantigens is one of the essential differences between tumor cells and normal cells, and therefore, the concept of using the identified neoantigens as vaccines to actively stimulate patients' autoimmune system and generate anti-tumor response has gained recognition. Theoretically, compared to other types of immunotherapy, the neoantigen vaccine, a new type of tumor immunotherapy, can induce strong specific immune response and elicit stable therapeutic effects.

This review will focus on the identification of neoantigens, designing of principles and clinical applications of neoantigen vaccines, and their combinations with other traditional or non-traditional antitumor therapies.

\section{Neoantigens}

Neoantigens, which are non-autologous proteins with individual specificity, are generated by non-synonymous mutations in the tumor cell genome [30]. Owing to its strong immunogenicity and lack of expression in normal tissues, it is now an important target for tumor immunotherapy. Sixty years ago, Prehn et al. [31] proposed that tumor cells can express neoantigens from DNA with non-synonymous mutations. In the 1980s and 1990s, scientists hypothesized that tumor-specific antigens are present on the surface of tumor cells, which can be recognized and bound by patients' human leukocyte antigen
(HLA) molecules, thereby activating specific $\mathrm{T}$ cells and inducing anti-tumor immune responses [32]. However, the traditional cloning methods are expensive and cannot always accurately identify tumor neoantigens, which limits the application and development of neoantigens as tumor vaccines. The rapid development of high-throughput sequencing technology, including whole-genome sequencing and the whole-exon sequencing, which are now less expensive and more convenient than they have been in the past, has led to explosion of sequencing data and identification of thousands of tumor-associated genes. Mutations affecting the process of tumorigenesis and development have also been identified [33-35], and studies are focusing on neoantigens that can be specifically recognized by $\mathrm{T}$ cells.

Neoantigens, a class of tumor-specific antigens, differ from the traditional tumor-associated antigen (TAA). TAA is not unique to tumor tissue as it is also present in normal tissues; it is highly expressed in proliferating tumor cells expressing HER2, MART-1, MUC1, and MAGE [36]. However, in vivo experiments by Prehn et al. [31] showed that antigens that elicit strong tumor rejection tend to exhibit strong individual specificity. Therefore, compared to TAAs, neoantigens possess stronger immunogenicity and higher affinity toward $\mathrm{MHC}$, and are not affected by central immunological tolerance. Using an ultraviolet light-induced mouse tumor model, Monach et al. [37] showed for the first time that tumor neoantigens can be targeted for cancer immunotherapy. The larger the difference between mutation sequence and original coding sequence, the more obvious the "non-self" feature of the abnormal protein and stronger the immunogenicity. Point mutations account for $95 \%$ mutations in tumors, whereas insertion-deletions (indels) and frame-shift mutations account for the rest $[38,39]$. The amino acid sequence and spatial structure changes caused by indel or frameshift mutations were more obvious, and the mutant peptide had a stronger affinity to $\mathrm{MHC}$ and was more likely to be recognized as a neoantigen by $\mathrm{T}$ cells [40]. However, due to the poor immunogenicity of a variety of tumors, or the decline of patients' autoimmune system function, the proportion of $\mathrm{T}$ cells spontaneously recognizing endogenous neoantigens is about 1-2\% [41], therefore designing specific vaccines on the basis of obtaining efficient neoantigens will be an effective tumor immunotherapy.

\section{Identification and prediction of neoantigens}

Neoantigens are highly individual-specific and usually do not involve known oncogenes. Hence, identification of neoantigens is critical for tumor vaccine therapy. Sequencing depth, quality of tumor tissue, source of the sequencing material, single nucleotide variants (SNV) 
algorithm, and other factors affect neoantigen identification [42-44]. The first step in neoantigen recognition is often the rapid comparison of the DNA sequences of tumor cells and normal cells using high-throughput sequencing techniques. As mutations in tumor cells are complex and include non-coding mutations and nonsense mutations, expression and screening of mutant proteins from these mutated DNA sequences are challenging [45]. With the development of sequencing technology and bioinformatics algorithms, the accuracy and reliability with which neoantigens can be predicted and identified have increased. The whole-exon sequencing technology can identify neoantigens with high efficiency, wide coverage, and low false negative rate. Currently, the majority of neoantigens are identified using the whole-exon sequencing technology [46].

Whether mutations can form tumor neoantigens depends on several factors: 1) whether the mutated sequence can be translated into protein; 2) whether the mutated protein can be processed into peptides and presented; 3) affinity between the mutated peptide and MHC molecules of the patients; 4) affinity of mutant
peptide-MHC complex with T cell receptor (TCR) [47]. Therefore, the prediction of neoantigens requires not only identification of genome-expressed mutations, but also data regarding patients' MHC types. Currently, various types of software applications are being used for the identification of neoantigens [48-51], and some commonly used software packages are listed in Table 1.

In the process of defining the specificity of the antitumor immune response, MHC-II type molecules present antigens, which are recognized by CD $4+\mathrm{T}$ cells. However, owing to the uniqueness of MHC-II structure and the complexity of the process via which peptides combine with MHC-II molecules, powerful and abundant databases on these interactions are lacking [67], Therefore, further development of bioinformatics is required to improve identification and evaluation of neoantigens.

\section{Principle of neoantigen vaccines}

Unlike common prophylactic vaccines, tumor vaccines are administered to patients with malignant tumors, supplemented by appropriate adjuvants, to activate the patient's autoimmune response and kill the tumor cells

Table 1 The summary of neoantigen prediction software

\begin{tabular}{ll}
\hline Software & Principle \\
\hline HLAminer [52] & $\begin{array}{l}\text { Based on the shotgun sequencing database from Illumina platform, the HLA type was predicted by orienting } 2012 \\
\text { the assembly of shotgun sequence data and comparing it with the reference allele sequence database }\end{array}$
\end{tabular}

VariantEffect Predictor Tool Automate annotations in a standard way to reduce manual review time, annotate and prioritize variants 2016 [53]

NetMHCpan [54]

UCSC browser [55]

CloudNeo pipeline [56]

OptiType [57]

ATHLATES [58]

pVAC-Seq [59]

MuPeXI [60]

Strelka [61]

Strelka2 [62]

VarScan2 [63]

Somaticseq [64]

SMMPMBEC [65]

NeoPredPipe [66]
Sequence comparison method based on artificial neural network, and predict the affinity of peptide-MHC-I type molecular

Based on sequence search, the fusion of multiple databases can provide fast and accurate access to any gene segment

Docker container was used to complete the tasks in the workflow. After the mutant VCF file and bam file representing HLA typing were input respectively, the HLA affinity prediction of all mutant peptides was obtained

The HLA typing algorithm based on integer linear programming provides sequencing databases including RNA, exome and whole genome

Assembly, allele recognition and allele pair inference were applied to short sequences, and the HLA genotyping at allele level was achieved by exon sequencing

To integrate tumor mutation and expression data and identify personalized mutagens by tumor sequencing

The extraction and induction of mutant peptides can roughly identify tumor-specific peptides, predict their immunogenicity, and evaluate their potential for new epitopes

Based on a new Bayesian model, the matching tumor-normal sample sequencing data was used to analyze and predict somatic cell variation, with high accuracy and sensitivity

Based on the mixed model, the error parameters of each sample insertion or deletion were estimated, and the liquid tumor analysis was improved

Somatic and copy number mutations in tumor-normal exome data were detected by heuristic statistical algorithm

Based on a randomized enhancement algorithm, more than 70 individual genome and sequencing features were extracted for each candidate site to accurately detect somatic mutations

Using matrix as a Bayesian prior, based on the optimal neural network predicting peptide with MHC-I type molecules

Based on a pipeline connecting commonly used bioinformatic software via custom python scripts to provide neoantigen burden, tumor heterogeneity, immune stimulation potential and HLA haplotype of patients 
[68-70]. Mutations in tumor cells change the amino acid sequences of proteins, which are then translated and processed into short peptides [71] called tumor neoantigens. As non-autoantigens, neoantigens are exposed to MHC molecules, which subsequently trigger the body's antitumor immune response.

In 1891, Dr. William Coley, the pioneer of tumor immunotherapy, used Coley's toxin (inactivated Streptococcus pyogenes and Serratia marcescens) for intratumoral injection to stimulate the patient's immune system, following which, occasional continuous tumor regression was observed [72]. Kugler et al. [73] fused tumor cells with dendritic cells using electrofusion technology; the fused cells not only expressed the tumor antigen, but also possessed the co-stimulation ability of dendritic cells. In patients with renal cancer, the fusion cells induced proliferation of autologous $\mathrm{T}$ lymphocytes and differentiation of cytotoxic lymphocytes (CTLs). Owing to technological limitations, the design of earlier tumor vaccines was relatively simple, and it was difficult to accurately locate the immunological target. Despite a certain degree of anti-tumor effect, the results were far from expected.

The therapeutic effect of tumor vaccines often depends on the difference in the expression of the targeted antigen between tumor cells and normal cells. As foreign antigens, neoantigens can not only enhance the antitumor immune response, but also reduce the risk of autoimmunity. Hence, neoantigen-activated $\mathrm{T}$ cells can produce highly active $\mathrm{T}$ cells, TCRs of which show stronger affinity toward MHC-neoantigen-peptide complexes and avoid clearance by central immune tolerance [74]. Among the non-synonymous mutations in the genome of cancer cells, driver mutations are special as they provide selective growth advantages for cancer cells. Compared to non-driver mutations, driver mutations have an obvious clonal tendency [75] and are possibly present in all cells of tumor tissues. Schumacher et al. [76] observed that accumulation of monoallelic point mutations in isocitrate dehydrogenase type 1 (IDH1) is an early and decisive event in the development of glioma subsets and other types of tumors, which can lead to the occurrence of new enzyme functions, genome hypermethylation, production of the oncogenic metabolite 2hydroxyglutarate (2-HG), genetic instability, and malignant transformation of cells [77-79]. The IDH1 peptide was used to vaccinate mice, which triggered an MHC-II type effective and restrictive anti-tumor immune response. Owing to the rapid development of sequencing technology and the continuous optimization of bioinformatics algorithms, researchers can now accurately identify tumor neoantigens and predict their MHC affinity and immunogenicity, resulting in the development of personalized medicine. Based on the definition of neoantigens or driving antigens, various types of cancer cell vaccines have been designed, including tumor cell vaccine [80], long peptide vaccine or protein vaccine $[81,82]$, genomic vaccine [83], and DC-based vaccine $[84,85]$.

With the optimization of the prediction algorithm of immunogenicity, research on tumor vaccines targeting neoantigens has progressed rapidly, and hopefully neoantigen vaccines will soon completely replace tumor vaccines targeting shared TAAs (Fig. 1).

\section{Clinical progress}

Traditional tumor vaccines mainly target TAAs, which are shared between tumor cells and normal cells [86]. Owing to the presence of central immunological tolerance in the thymus, the active $\mathrm{T}$ cells that recognize TAA or other autoantigens are likely to be eliminated during development, which affects the efficacy of tumortargeted vaccines $[87,88]$. Several clinical trials targeting TAAs have shown that long-term therapeutic effects are difficult to achieve with anti-tumor vaccines [86]. P1A is the first recognized non-mutated tumor-related antigen. Sarma et al. [89] developed transgenic mice that can express P1A-specific receptor on the surface of all $\mathrm{T}$ cells. For P1A-expressing tumor cells, T cells were unable to produce sufficiently strong killing effect.

Current genomics and bioinformatics technologies can identify tumor-specific missense mutant proteins that act as tumor neoantigens in tumor vaccines [90]. Several clinical trials have shown that neoantigens can be recognized by CD8+ and CD4 + T cells in tumor tissue, and thus trigger an anti-tumor immune response in vivo [91, 92]. Castle et al. [93] used SLPs derived from 50 effective mutations to immunize B16F0 mouse melanoma models. Results showed that neoantigen peptide vaccines targeting MUT30 and MUT44, two mutated antigens, had significant preventive and therapeutic effects in mouse tumor models.

Carreno et al. [94] was the first to report that DCs loaded with neoantigens can trigger specific $\mathrm{T}$ cell responses in patients with melanoma. In this study, whole-exon sequencing, computer-simulated epitope prediction, and immunohistochemistry were used to identify neoantigens on tumor cells. This was also the first study to show that the antigen can be identified by CTLs in three patients with melanoma. Subsequently, DCs loaded with neoantigens were cultured in vitro for autologous transfusion. Results showed that the DCbased neoantigen-specific vaccine triggered neoantigenspecific $\mathrm{T}$ cell response that was not detected before injection and enhanced the existing immune response. Of the three patients with melanoma, two were stable, and one showed no side effects or recurrence.

The RNA neoantigen vaccine has unique advantages. When adequate tumor tissue is not available, RNA 


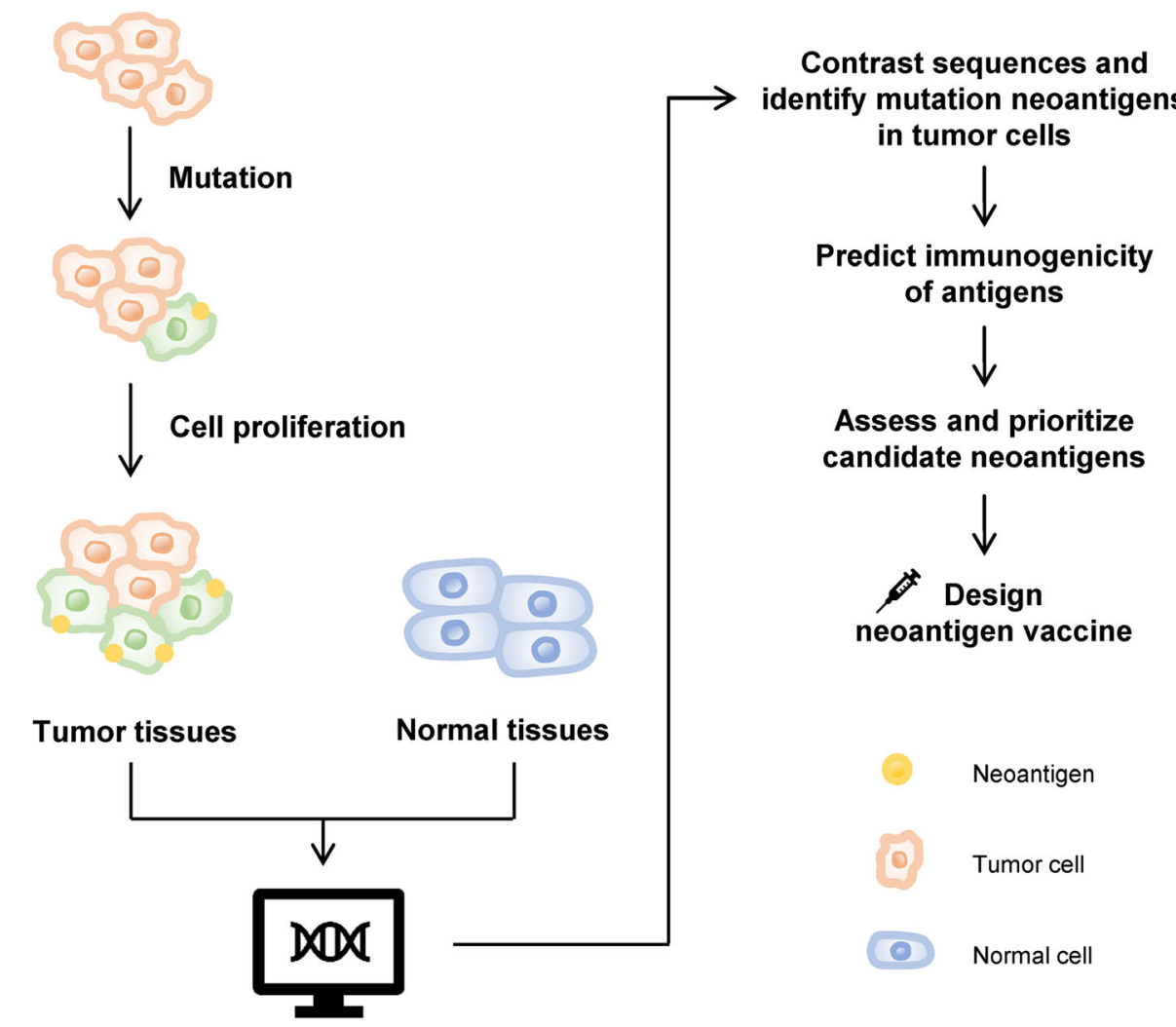

Fig. 1 Mutations in tumor tissue produce neoantigens. Clonal neoantigens can be expressed by a large number of proliferating tumor cells. Various software packages were used to compare the sequence differences between tumor cells and normal cells, and to predict and prioritize the immunogenicity of antigens for screening the optimal tumor neoantigens

extracted from a small number of cancer cells is amplified for vaccine preparation. Compared to DNA vaccines, RNA vaccines can avoid integration into host cell genome and avoid potential risks. Sahin et al. [50] was the first to identify neoantigens using the next generation sequencing (NGS) database, and prepared RNA vaccines capable of encoding neoantigens using computer simulation and predictive binding. These RNA molecules were previously shown to be captured by DCs in lymph nodes [95]. In total, 13 patients with melanoma received the RNA vaccine, eight of whom had no tumor development during follow-up. Immunosurveillance analysis of peripheral blood mononuclear cells (PBMCs) in patients showed that RNA vaccines can enhance the existing neoantigen-specific $\mathrm{T}$ cell response and induce new $\mathrm{T}$ cell response. Ott et al. [49] identified neoantigens and used bioinformatics algorithm to predict the combination of neoantigens and MHC-I molecules; the prepared SLP vaccine was injected in six patients with surgical resection of the tumor. Results showed that the tumor did not recur in four patients in the 32 months after inoculation.

In a recent study, a neoantigen vaccine was shown to affect glioblastoma, which lacks $\mathrm{T}$ cell infiltration and has low mutation rate. Hilf et al. [96] prepared two highly personalized vaccines and inoculated 15 patients with HLA-A*02:01- or HLA-A*24:02-positive glioblastoma, which elicited continuous $\mathrm{T}$ cell response and improved patients' median total survival time to 29.0 months. Keskin et al. [97] administered neoantigen vaccine to glioblastoma patients after surgical resection and conventional radiotherapy and observed that the vaccine activated specific $\mathrm{T}$ cells, which migrated from the peripheral blood into the brain, changing the immune environment of glioblastoma.

In addition, clinical trials have shown that for patients with early-stage tumors, the tumor vaccine is more effective, while for patients with late-stage tumors, it is less effective than expected. Hanna et al. [98] conducted three multi-mechanism, prospective, randomized, controlled clinical trials to assess therapeutic efficacy in patients with stage II and III colon cancer after surgical removal of tumor and injection of a tumor vaccine. They monitored four parameters, namely recurrence time, total survival period, disease-free survival period, and survival without recurrence. Results showed that the disease-free survival period of patients receiving tumor vaccine was longer than those in the control group, and the 
effect of the treatment on patients with stage II disease was significantly better than that on patients with stage III disease. Therefore, timely treatment with tumor vaccine can yield results closer to the expected effect.

Overall, RNA-, SLP-, DC-based vaccines, and other neoantigen vaccines have been tested in strict phase I clinical trials, and the results were in agreement with the expected results. These preliminary results indicated that neoantigen vaccines based on DCs, SLP, and RNA are safe and have the ability to induce CD8+ and CD4+ specific $\mathrm{T}$ cell responses, highlighting the considerable potential of this immunotherapy (Fig. 2).

\section{Combination of neoantigen vaccine with other therapies} Although neoantigen vaccines can stimulate autoimmune response, tumor cells possess various immune escape mechanisms; in addition, the tumor microenvironment also interferes in the function of immune cells, and even inhibits immune response [99-106], which impedes the vaccine from exhibiting its optimal effect in vivo. Yadav et al. [51] used mutated DPAGT1, REPS1, and ADPGK to prepare peptide vaccines that can delay the growth of tumor cells in mouse models; at the same time, they observed that neoantigen-specific $T$ cells expressed high levels of PD-1 and TIM3 receptors, which acted as negative regulators of immune response, and even induced apoptosis of $\mathrm{T}$ cells, suggesting that $\mathrm{T}$ cells become dysfunctional during this process [107]. Therefore, combination of neoantigen vaccine and other therapies is required to achieve the expected effect of the vaccine.

Tumor vaccines stimulate the patients' immune system, especially the response of specific CD8+ T cells [68]; however, interferon gamma (IFN $\gamma$ ) produced by CD8+ and Th1 CD4+ cells regulate the expression of PD-L1 [108-110]. PD-L1 expression in tumor cells is upregulated when attacked by $\mathrm{T}$ cells [111]. Therefore, tumor vaccines induce the production of specific $\mathrm{T}$ cells and simultaneously upregulate the expression of PD-L1, inhibiting the function of tumor vaccines $[112,113]$. In addition, while the immune system is activated, the expression of $\mathrm{T}$ cell surface reporter CTLA-4 is correspondingly increased, which binds with the

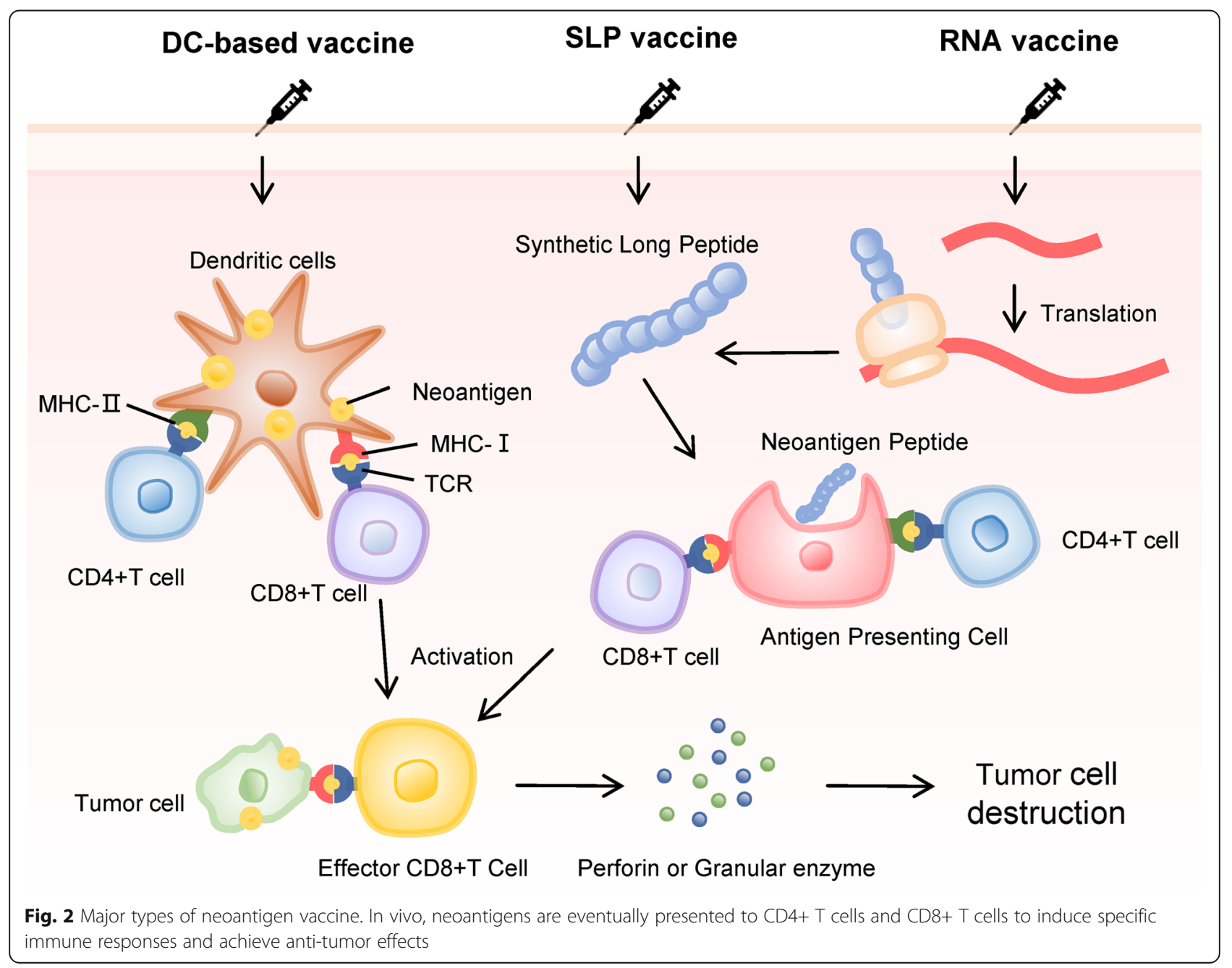


ligand B7-1/B7-2 on Antigen-presenting cells and plays an immunosuppressant effect. Checkpoint inhibition therapy involves the use of specific monoclonal antibodies, namely, anti-CTLA-4 [114], anti-PD-1 [115], and anti-PD-L1 antibodies [116], which bind to the immune checkpoint proteins of $\mathrm{T}$ cells to remove the inhibition of $\mathrm{T}$ cell function by tumor cells [117]. This therapy has a lasting clinical effect and is effective for patients with multiple malignant tumors [118], although patients lacking tumor-specific effector $\mathrm{T}$ cells do not respond to immune checkpoint inhibition therapy [119-121].

Comparative studies have shown that the combination of tumor vaccine and immunosuppressive therapy is more effective than monotherapy $[122,123]$. Curran et al. [124] designed mouse models to show that the vaccine secreting granulocyte/macrophage-colony stimulating factor (GM-CSF) or Flt3-ligand, combined with PD1 and CTLA-4 blocking therapy, can effectively prolong the survival period and improve the ratio of effector cells to regulatory cells in the tumor microenvironment of mice. Ott et al. [49] reported that six surgically resected patients with melanoma were injected with synthetic neoantigen peptides. Two of them had poor therapeutic effects and achieved complete anti-tumor immune responses after treatment with the PD-1 antibody.

Combinations of neoantigen vaccine and adaptive $\mathrm{T}$ cell therapy have also been successfully used to achieve anti-tumor response. Matthias et al. [125] reported that mutation-specific TCR might provide efficient antitumor response under appropriate condition. The team used ultraviolet radiation to generate the mouse tumor model and divided the tumor tissue into 20 fragments, followed by analysis of the antigenic composition of different parts, and finally obtained the main neoantigens existing in all the 20 tumor tissue blocks [126]. The antigen is called mp68 and Matthias's team designed T cells that express a high-affinity mp68 TCR, which was administered to mice. Results showed that the therapy can destroy intratumorous blood vessels and destroy larger, longer-lived solid tumors. Using full excision sequencing, Tran et al. [127] demonstrated that the lymphocyte infiltrate of tumors from patients with metastatic cholangiocarcinoma contained $\mathrm{CD} 4+\mathrm{T}$ helper 1 (Th1) cells, which can identify a mutated HLA-II antigen from erbb2 interacting protein (ERBB2IP) in the carcinoma. After the incorporation of tumor infiltrating lymphocytes (TILs) containing $\sim 25 \%$ neoantigen-specific auxiliary Th1 cells into tumor tissues, the target lesions of the patients reduced, and the stable time of the disease was prolonged, leading to significant tumor regression. In the current study, Song et al. [128] sequenced whole exome and transcriptomes in patients with epithelial ovarian cancer (EOC) to identify neoantigen candidates and then analyzed the reactions of neoantigen-specific CD4+ and CD8+ T cell response in tumor or the peripheral blood. The specific $\mathrm{T}$ cell receptors (TCR) were transferred to peripheral blood $\mathrm{T}$ cells, making them with a neoantigen reactivity. It is another feasible strategy to eventually achieve the personalized trans- $T$ cells transfer immunotherapy.

However, CAR-T therapy has limited efficacy due to the fact that CAR-T cells transfer into the patient through intravenous injection, as the blood circulates to the tumor site, $\mathrm{T}$ cells could identify neoantigens and be activated, while the microenvironment of solid tumors blocks CAR-T cells. Ma et al. [129] designed amphiphilic ligands (amph-ligands) in the latest study, which effectively alleviated this problem. The head of amph-ligands contain antigens to activate the CAR-T cells, at the other end, amph-ligands are equipped with long tail of lipids, which binds to free albumin in the blood and rapidly arrives at lymph nodes to join CAR-T cells. Firstly, the researchers demonstrated that this type of amph-ligands vaccine can dose-dependent activate CAR- $T$ cells to exert tumor killing effect in vitro. Then they inoculated amph-pepvIII vaccine and EGFRvIII CAR-T cells in glioma mice, observed significant amplification and intratumoral infiltration of CAR-T cells in peripheral blood. Subsequent experiments in various mouse tumor models eventually achieved the complete elimination of $60 \%$ of mouse tumors, showing the great potential of the combination of neoantigen and CAR-T therapy.

Several factors can lead to immune dysfunction in the tumor microenvironment, such as T-Regulatory cells (Tregs), myeloid-derived suppressor cells (MDSCs), potassium, and immunosuppressive DC cells that inhibit the activity of T cells [130]. Spranger et al. [109] showed that various immunosuppressive factors are immune-intrinsic. After the infiltration of effector T cells, FoxP3+ Tregs is recruited at tumor sites as a negative feedback regulatory mechanism driven by CCR4-binding chemokine along with induced proliferation component, indicating that tumor vaccines could induce effector $\mathrm{T}$ cells and increase Tregs population in the tumor at the same time. Klages et al. [131] observed that tumor growth was retarded when a transgenic diphtheria toxin receptor was used to prostrate Tregs in a mouse model of melanoma, thereby significantly improving the anti-cancer effect of the tumor vaccine. Other two studies conducted by Casares et al. [132, 133] showed that FoxP3 inhibitory peptide P60 occupied the intermediate domain of FoxP3, inhibited its homologous dimerization and binding with transcription factors, attenuated the activity of Tregs in vivo and in vitro, and enhanced the efficacy of tumor vaccines in mouse models.

In addition, tumor necrosis can inhibit the activity of anti-tumor T cells. After tumor cell necrosis, intracellular potassium ions are released into the extracellular 
space and are enriched in tumor-specific effector T cells, which can inhibit the activity of Akt protein kinase, enhance the inhibition of potassium ion-induced $\mathrm{T}$ cell function, and prompt immune escape of tumor cells [134]. Inhibition of this potassium-induced immune suppression, combined with a tumor vaccine, can enhance the killing effect of tumor-specific $\mathrm{T}$ cells.

Traditional treatments such as radiotherapy and chemotherapy can also enhance the role of neoantigen vaccines. Studies have shown that chemotherapy or radiotherapy can induce tumor cells to release more antigens. The combination of neoantigen vaccine and chemoradiotherapy can circumvent this problem when the number of tumors neoantigens is too low to activate T-cell response [135]. Radiotherapy can also enhance the transport of $\mathrm{T}$ cells into tumor tissue and increase the intensity of specific anti-tumor immune response [136]. In addition, several reports have shown that certain chemotherapeutic drugs can enhance the antitumor activity of adoptive $\mathrm{T}$ cells $[137,138]$, macrophages [139], and tumor vaccines [140, 141]. For example, pretreatment with CTX (cyclophosphamide) and other preparations, followed by tumor vaccine injection, can enhance the number and functional activity of neoantigen-specific $T$ cells. The optimal immunomodulatory dose is reached when the dose of the chemotherapeutic drug is higher than the dose at which cytopenia is induced [142]. In addition, chemoradiotherapy can reduce immune suppression in the tumor microenvironment [143]. Although application of radiotherapy and chemotherapy alone cannot completely eliminate large numbers of tumor cells, combination with neoantigen vaccines shows considerable prospects. Immunologicallymediated and radiation-driven personalized systemic therapy model [144] is also a new concept in the field of personalized therapy.

Compared to traditional therapy and vaccines based on shared antigens, neoantigen vaccine has obvious advantages and lower side effect; however, effective and long-term therapeutic effects are not observed when it is used for monotherapy. Nonetheless, combined with other methods, such as immune checkpoint inhibition and immune inhibition in the tumor microenvironment, it can produce stronger antitumor response [49] (Fig. 3).

\section{Disadvantages and future directions}

Neoantigen vaccines alone cannot achieve complete elimination of malignant tumors. Melief et al. [145] postulated that insufficient maturity of the selected and recognized neoantigens is one of the reasons why neoantigen vaccines cannot completely eradicate tumors. The occurrence and development of tumor is a dynamic evolutionary process characterized by genetic instability. Many types of mutations are generated, cloned, altered, and lost from the tumor cell genome. Recent technology allows analysis of the genomes of single tumor samples collected at specific time points, which, however, does not provide information regarding the heterogeneity in tumors [146, 147]. Vaccines can only kill a small number of tumor cells if the neoantigens targeted by the vaccine are derived from mutated subclones, which restricts clinical effect [148]. As driver mutations possibly exist in all cells within a certain tumor, designing of vaccines targeting these neoantigens is important; however, it is often difficult to translate a mutation to a neoantigen. In melanoma, only about $8 \%$ neoantigens are derived from driver mutations, and $92 \%$ are from non-driver mutations [47]. Methods of identifying effective and common neoantigens and improving activation of immune cells are challenges for tumor vaccine designing.

The use of neoantigen vaccines is also limited by the diversity of somatic mutations in different tumor types and their individual specificity. Studies have shown that the immune activity correlated positively with the tumor mutation burden (TMB) of tumors [149]. Only 10\% of the non-synonymous mutations in tumor cells can generate mutant peptides with high MHC affinity [40], while only $1 \%$ peptides with high $\mathrm{MHC}$ affinity can be recognized by $\mathrm{T}$ cells in patients [150]. Therefore, theoretically, the higher the TMB, the more neoantigens can be recognized by $\mathrm{T}$ cells in tumors. The TMB varies considerably with different types of malignant tumors. Tumors with high TMB, such as melanoma, have a higher response rate to immunotherapy, whereas tumors with generally low TMB are not suitable for the existing neoantigen vaccine system. Common chromosomal abnormalities in nasopharyngeal carcinoma are predominant in southeast Asia and some other regions, but the mutation rate is lower than those of other types of malignant tumors; furthermore, the median rate of somatic cell mutation per megabase is one [151], indicating that identification of neoantigens in the tumor tissues of nasopharyngeal carcinoma is challenging. Owing to significant differences in mutations among the three subtypes of nasopharyngeal carcinoma [152], the TMBs varied and the neoantigens produced were not identical.

But this is not always the case, as pediatric tumors often show significantly fewer somatic cell mutations, Zamora et al. [153] have shown that although children with acute lymphoblastic leukemia TMB is lower, but still could be induced strong antitumor immune response, which suggests the hematological malignancy may have better immunogenicity. Parkhurst et al. [154] performed highthroughput immunoscreening and whole exome sequencing of 75 patients with common gastrointestinal tumors, and identified 124 neoantigen-reactive tumor-immersed lymphocyte populations, which showed that even though some common epithelial tumors were considered to be 


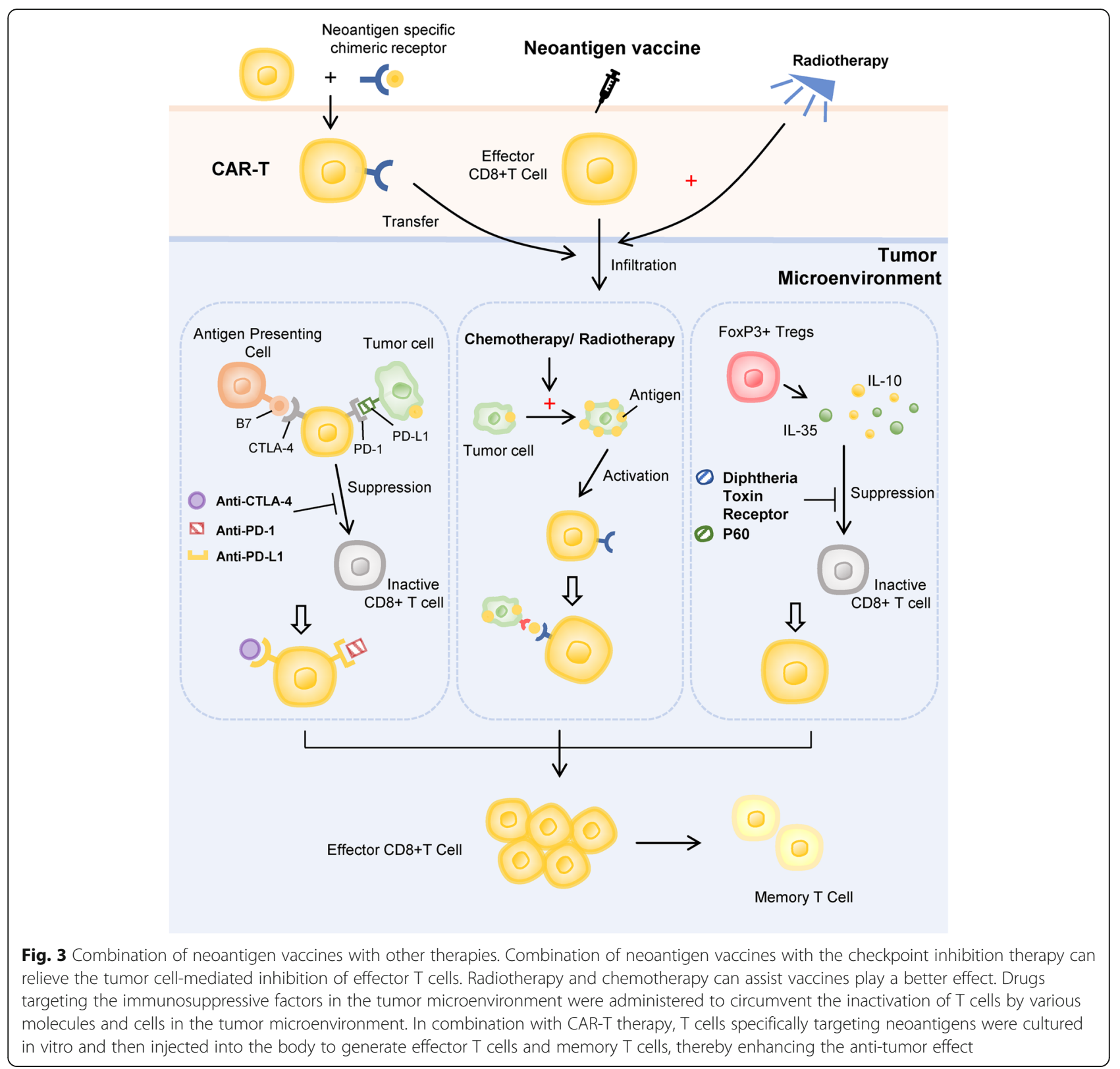

low-immunogenicity, they also had the function of activating immune recognition and offered the possibility of immunotherapy on some extent.

Moreover, the neoantigens produced by each tumor are almost specific even for the same tumor type and there is no sharing between patients [155], and the probability of different individuals developing the same neoantigens is extremely low [156]. Therefore, neoantigens must be searched based on tumor types. Thus, large differences among tumor types and individuals limit the use of tumor vaccines targeting mutated neoantigens.

Owing to the limitation of the whole-exon sequencing technology, previous neoantigen assays are often limited to $2 \%$ of the coding sequence of the human genome.
Recently, Perreault et al. developed a new protein genomics approach for analyzing non-coding regions, and their results showed that any type of non-coding region can produce abundant aberrantly expressed tumor-specific antigens (aeTSAs), a small part of which is generated by the mutation, whereas the majority arises from epigenetic changes in atypical translation events. The number of aeTSAs exceeds that of the neoantigen produced by mutations in coding regions [157]. Unlike the highly individual specificity of mutated neoantigens, aeTSAs can be shared by multiple individuals with tumors [158, 159]. Identification of more efficient neoantigens and aeTSAs in non-coding regions was a breakthrough in the field of tumor vaccines. 
Immune escape of tumor cells is a critical issue impeding the efficacy of tumor vaccines. Tran et al. [160] observed loss of heterozygosity of chromosome 6 , which encodes HLA-C*08:02, in 4095 patients, and showed that this molecule is essential for adoptive KRAS G12Dspecific $\mathrm{T}$ cells to recognize tumors, thereby providing direct evidence regarding immune escape of tumor cells. Loss of heterozygosity of the HLA site limits clinical responses to tumor vaccines targeting neoantigens or adoptive $\mathrm{T}$ cell therapies. In addition to antigen loss, tumor cells possess various complex immune escape mechanisms, including suppression of immune checkpoints such as PD-1 and CTLA-4, immunosuppressive effect of various cells in the tumor microenvironment [161], and release of ions or proteins inside tumor cells after necrosis, all of which compromise the recognition of neoantigens by $\mathrm{T}$ cells and their activation. Neoantigen vaccine combined with other immunotherapies can prevent partial immune escape; however, many mechanisms are yet to be clearly elucidated, which impedes the clinical application of neoantigen vaccines. At the same time, the combination of tumor vaccines with other traditional therapies, such as chemoradiotherapy and targeted therapy, show immense potential for development. In addition, Muhammad et al. [162] adopted a different strategy for this problem recently. They transfected monocyte derived DC with neoantigen encoding mRNA to prime autologous naive CD8+ T cells in healthy donors. This program makes the activation of T-cells unaffected by the immunosuppressive environment of tumor hosts, which provides a new idea for us.

Although the current sequencing technology has triggered rapid development [45], identification and verification of neoantigens are still time-consuming and expensive, and the process of preparing vaccines from tissue samples usually takes $3-5$ months $[49,50]$. This long preparation period seriously limits the clinical application of neoantigen vaccines. Problems such as the high demand for tumor tissue in the identification process and the low yield of peptides after immunoaffinity purification are the technical obstacles that are currently difficult to overcome [163]. There is still room for further optimization of the neoantigen prediction algorithm. In addition to predicting the combination of different MHC molecules with neoantigens, it is necessary to predict potential neoantigens generated by gene fusion, indels, and other changes.

\section{Conclusion}

Neoantigens are mutated antigens specifically expressed by tumor tissue and are not expressed on the surface of normal cells. Development of sequencing technology has improved the accuracy of identification and localization of neoantigens. Neoantigens are highly specific for individuals, and hence, tumor vaccines targeting neoantigens can effectively induce tumor-specific $\mathrm{T}$ cells in patients without killing normal cells, thereby achieving personalized precision treatment. As an emerging antitumor immunotherapy, neoantigen vaccine has achieved the expected therapeutic effect in several trials, improving the quality of patients' lives to a certain extent and extending the survival period. SLP-, RNA-, DNA-, and DC-based vaccines, as well as other types of vaccines, have shown excellent safety and induction ability. The development of bioinformatics will further improve the recognition and identification of neoantigens.

Owing to the immune escape mechanism of tumor cells, neoantigen vaccines may not be able to exert their expected killing effect after inducing specific $\mathrm{T}$ cells, which is also one of the limitations regarding the application of tumor vaccines. Changes occur constantly during tumorigenesis and development, which enables tumors to survive in the complex immune environment. Further in-depth understanding of oncology and tumor immunology, and elucidation of the immune suppression and escape mechanisms of tumor tissue, will aid in developing more effective strategies.

\section{Abbreviations \\ 2-HG: 2-hydroxyglutarate; aeTSA: Aberrantly expressed tumor-specific antigen; CTL: Cytotoxic lymphocyte; CTLA-4: cytotoxic T lymphocyte antigen 4; CTX: Cyclophosphamide; DC: Dendritic cell; GM-CSF: Granulocyte/ macrophage-colony stimulating factor; HLA: Human leukocyte antigen; IDH1: Isocitrate dehydrogenase type 1; IFNy: Interferon gamma; Indels: Insertion-deletions; MDSC: Myeloid-derived suppressor cell; MHC: Major histocompatibility complex; NGS: Next generation sequencing; PBMC: Peripheral blood mononuclear cell; PD-1: Programmed cell death protein 1; SLP: Synthetic long peptide; SNV: Single nucleotide variant; TAA: Tumor-associated antigen; TCR: T cell receptor; TIL: Tumor infiltrating lymphocyte; TMB: Tumor mutation burden; Treg: T-Regulatory cell}

Acknowledgements

Not applicable.

\section{Authors' contributions}

MP, YZM, YAW, PW and YJZ collected the related paper and finished the manuscript and figures. $W X, Z Y Z$ gave constructive guidance and made critical revisions. FX, CG, XW, YL, XLL, GYL participated in the design of this review. All authors read and approved the final manuscript.

\section{Funding}

This study was supported by grants from The National Natural Science Foundation of China (81572787, 81672683, 81672993, 81672688, 81702907, 81772901, 81772928, 81803025 and 81872278), the Overseas Expertise Introduction Project for Discipline Innovation (111 Project, No. 111-2-12), and the Natural Science Foundation of Hunan Province (2016JC2035, 2017SK2105, 2018JJ3704, 2018JJ3815, 2018SK21210 and 2018SK21211).

Availability of data and materials Not applicable.

Ethics approval and consent to participate Not applicable.

Consent for publication Not applicable. 


\section{Competing interests}

The authors declare that they have no competing interests.

\section{Author details}

${ }^{1} \mathrm{NHC}$ Key Laboratory of Carcinogenesis and Hunan Key Laboratory of Translational Radiation Oncology, Hunan Cancer Hospital and The Affiliated Cancer Hospital of Xiangya School of Medicine, Central South University, Changsha, Hunan, China. ${ }^{2}$ Key Laboratory of Carcinogenesis and Cancer Invasion of the Chinese Ministry of Education, Cancer Research Institute, Central South University, Changsha, Hunan, China. ${ }^{3}$ Hunan Key Laboratory of Nonresolving Inflammation and Cancer, Disease Genome Research Center, the Third Xiangya Hospital, Central South University, Changsha, Hunan, China. ${ }^{4}$ DEPARTMENT OF MEDICINE, Comprehensive Cancer Center Baylor College of Medicine, Alkek Building, RM N720, Houston, Texas, USA.

Received: 19 April 2019 Accepted: 14 August 2019

Published online: 23 August 2019

\section{References}

1. Bray F, Ferlay J, Soerjomataram I, Siegel RL, Torre LA, Jemal A. Global cancer statistics 2018: GLOBOCAN estimates of incidence and mortality worldwide for 36 cancers in 185 countries. CA Cancer J Clin. 2018;68:394-424.

2. Wu C, Li M, Meng H, Liu Y, Niu W, Zhou Y, et al. Analysis of status and countermeasures of cancer incidence and mortality in China. Sci China Life Sci. 2019;62:640-7.

3. Wei F, Wu Y, Tang L, Xiong F, Guo C, Li X, et al. Trend analysis of cancer incidence and mortality in China. Sci China Life Sci. 2017;60:1271-5.

4. Krall JA, Reinhardt F, Mercury OA, Pattabiraman DR, Brooks MW, Dougan M, et al. The systemic response to surgery triggers the outgrowth of distant immune-controlled tumors in mouse models of dormancy. Sci Transl Med. 2018;10. https://doi.org/10.1126/scitranslmed.aan3464.

5. Fan C, Tang Y, Wang J, Xiong F, Guo C, Wang Y, et al. The emerging role of Epstein-Barr virus encoded microRNAs in nasopharyngeal carcinoma. J Cancer. 2018;9:2852-64.

6. He $Y$, Jing $Y$, Wei $F$, Tang $Y$, Yang $L$, Luo J, et al. Long non-coding RNA PVT1 predicts poor prognosis and induces radioresistance by regulating DNA repair and cell apoptosis in nasopharyngeal carcinoma. Cell Death Dis. 2018;9:235.

7. Tang L, Wei F, Wu Y, He Y, Shi L, Xiong F, et al. Role of metabolism in cancer cell radioresistance and radiosensitization methods. J Exp Clin Cancer Res. 2018;37:87.

8. Wei F, Tang L, He Y, Wu Y, Shi L, Xiong F, et al. BPIFB1 (LPLUNC1) inhibits radioresistance in nasopharyngeal carcinoma by inhibiting VTN expression. Cell Death Dis. 2018;9:432.

9. Tsimberidou AM, Iskander NG, Hong DS, Wheler JJ, Falchook GS, Fu S, et al. Personalized medicine in a phase I clinical trials program: the MD Anderson Cancer Center initiative. Clin Cancer Res. 2012;18:6373-83.

10. Tsimberidou AM, Ringborg U, Schilsky RL. Strategies to overcome clinical, regulatory, and financial challenges in the implementation of personalized medicine. Am Soc Clin Oncol Educ Book. 2013:118-25.

11. Tsimberidou AM, Wen S, Hong DS, Wheler JJ, Falchook GS, Fu S, et al. Personalized medicine for paGenome-wide analysis of 18 Epstein-Barr viruses isolated frotients with advanced cancer in the phase I program at MD Anderson: validation and landmark analyses. Clin Cancer Res. 2014;20: 4827-36.

12. Tsimberidou AM. Targeted therapy in cancer. Cancer Chemother Pharmacol. 2015;76:1113-32.

13. Thanarajasingam G, Thanarajasingam U, Ansell SM. Immune checkpoint blockade in lymphoid malignancies. FEBS J. 2016;283:2233-44.

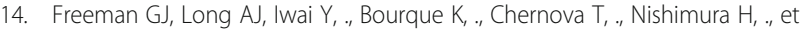
al. Engagement of the PD-1 immunoinhibitory receptor by a novel B7 family member leads to negative regulation of lymphocyte activation. J Exp Med, 2000:192:1027.

15. Krummel MF, Allison JP. CD28 and CTLA-4 have opposing effects on the response of T cells to stimulation. J Exp Med. 1995;182:459-65.

16. Leach DR, Krummel MF, Allison JP. Enhancement of antitumor immunity by CTLA-4 blockade. Science. 1996:271:1734-6.

17. Nishimura H, Nose M, Hiai H, Minato N, Honjo T. Development of lupus-like autoimmune diseases by disruption of the PD-1 gene encoding an ITIM motif-carrying immunoreceptor. Immunity. 1999;11:141-51.
18. Duan S, Guo W, Xu Z, He Y, Liang C, Mo Y, et al. Natural killer group 2D receptor and its ligands in cancer immune escape. Mol Cancer. 2019;18:29.

19. Wang YA, Li XL, Mo YZ, Fan CM, Tang L, Xiong F, et al. Effects of tumor metabolic microenvironment on regulatory T cells. Mol Cancer. 2018;17:168,

20. Xiong F, Deng S, Huang HB, Li XY, Zhang WL, Liao QJ, et al. Effects and mechanisms of innate immune molecules on inhibiting nasopharyngeal carcinoma. Chin Med J. 2019;132:749-52.

21. Xiang B, Snook AE, Magee MS, Waldman SA. Colorectal cancer immunotherapy. Discov Med. 2013;15:301-8.

22. Tchou J, Zhao Y, Levine BL, Zhang PJ, Davis MM, Melenhorst JJ, et al. Safety and efficacy of Intratumoral injections of chimeric antigen receptor (CAR) T cells in metastatic breast Cancer. Cancer Immunol Res. 2017;5:1152-61.

23. You F, Jiang L, Zhang B, Lu Q, Zhou Q, Liao X, et al. Phase 1 clinical trial demonstrated that MUC1 positive metastatic seminal vesicle cancer can be effectively eradicated by modified anti-MUC1 chimeric antigen receptor transduced T cells. Sci China Life Sci. 2016;59:386-97.

24. Tanaka M, Tashiro H, Omer B, Lapteva N, Ando J, Ngo M, et al. Vaccination targeting native receptors to enhance the function and proliferation of chimeric antigen receptor (CAR)-modified T cells. Clin Cancer Res. 2017;23: 3499-509.

25. Thistlethwaite FC, Gilham DE, Guest RD, Rothwell DG, Pillai M, Burt DJ, et al. The clinical efficacy of first-generation carcinoembryonic antigen (CEACAM5)-specific CAR T cells is limited by poor persistence and transient pre-conditioning-dependent respiratory toxicity. Cancer Immunol Immunother. 2017;66:1425-36.

26. Babbitt BP, Allen PM, Matsueda G, Haber E, Unanue ER. Binding of immunogenic peptides to la histocompatibility molecules. Nature. 1985;317: 359-61.

27. Bjorkman PJ, Saper MA, Samraoui B, Bennett WS, Strominger JL, Wiley DC. Structure of the human class I histocompatibility antigen, HLA-A2. J Immunol. 2005;174:6-19.

28. Cerottini JC, Engers HD, Macdonald HR, Brunner T. Generation of cytotoxic T lymphocytes in vitro. I. Response of normal and immune mouse spleen cells in mixed leukocyte cultures. J Exp Med. 1974;140:703-17.

29. Gillis S, Smith KA. Long term culture of tumour-specific cytotoxic T cells. Nature. 1977;268:154-6.

30. Srivastava PK. Neoepitopes of cancers: looking Back, looking ahead. Cancer Immunol Res. 2015:3:969-77.

31. Prehn RT, Main JM. Immunity to methylcholanthrene-induced sarcomas. J Natl Cancer Inst. 1957;18:769-78.

32. De Plaen E, Lurquin C, Van Pel A, Mariame B, Szikora JP, Wolfel T, et al. Immunogenic (tum-) variants of mouse tumor P815: cloning of the gene of tum- antigen P91A and identification of the tum- mutation. Proc Natl Acad Sci U S A. 1988;85:2274-8.

33. Alexandrov LB, Nik-Zainal S, Wedge DC, Aparicio SA, Behjati S, Biankin AV, et al. Signatures of mutational processes in human cancer. Nature. 2013;500: $415-21$

34. Tu C, Zeng Z, Qi P, Li X, Guo C, Xiong F, et al. Identification of genomic alterations in nasopharyngeal carcinoma and nasopharyngeal carcinomaderived Epstein-Barr virus by whole-genome sequencing. Carcinogenesis. 2018:39:1517-28.

35. Tu C, Zeng Z, Qi P, Li X, Yu Z, Guo C, et al. Genome-wide analysis of 18 Epstein-Barr viruses isolated from primary nasopharyngeal carcinoma biopsy specimens. J Virol. 2017;91. https://doi.org/10.1128/JVI.00301-17.

36. Li L, Goedegebuure SP, Gillanders WE. Preclinical and clinical development of neoantigen vaccines. Ann Oncol. 2017;28:xii11-7.

37. Monach PA, Meredith SC, Siegel CT, Schreiber H. A unique tumor antigen produced by a single amino acid substitution. Immunity. 1995;2:45-59.

38. Blank C, Brown I, Peterson AC, Spiotto M, Iwai Y, Honjo T, et al. PD-L1/B7H-1 inhibits the effector phase of tumor rejection by $T$ cell receptor (TCR) transgenic CD8+ T cells. Cancer Res. 2004;64:1140-5.

39. Snyder A, Makarov V, Merghoub T, Yuan J, Zaretsky JM, Desrichard A, et al. Genetic basis for clinical response to CTLA-4 blockade in melanoma. N Engl J Med. 2014:371:2189-99.

40. Chen DS, Mellman I. Elements of cancer immunity and the cancer-immune set point. Nature. 2017:541:321-30.

41. Karpanen T, Olweus J. The potential of donor T-cell repertoires in Neoantigen-targeted Cancer immunotherapy. Front Immunol. 2017:8:1718.

42. Horak P, Frohling S, Glimm H. Integrating next-generation sequencing into clinical oncology: strategies, promises and pitfalls. ESMO Open. 2016;1:e000094 
43. Karasaki T, Nagayama K, Kuwano H, Nitadori Jl, Sato M, Anraku M, et al. Prediction and prioritization of neoantigens: integration of RNA sequencing data with whole-exome sequencing. Cancer Sci. 2017;108:170-7.

44. Roberts ND, Kortschak RD, Parker WT, Schreiber AW, Branford S, Scott HS, et al. A comparative analysis of algorithms for somatic SNV detection in cancer. Bioinformatics. 2013;29:2223-30.

45. Li L, Goedegebuure P, Mardis ER, Ellis MJ, Zhang X, Herndon JM, et al. Cancer genome sequencing and its implications for personalized cancer vaccines. Cancers (Basel). 2011;3:4191-211.

46. van Buuren MM, Calis JJ, Schumacher TN. High sensitivity of cancer exomebased CD8 T cell neo-antigen identification. Oncoimmunology. 2014;3:e28836.

47. Schumacher TN, Schreiber RD. Neoantigens in cancer immunotherapy. Science. 2015;348:69-74

48. Gubin MM, Zhang X, Schuster H, Caron E, Ward JP, Noguchi T, et al. Checkpoint blockade cancer immunotherapy targets tumour-specific mutant antigens. Nature. 2014;515:577-81.

49. Ott PA, Hu Z, Keskin DB, Shukla SA, Sun J, Bozym DJ, et al. An immunogenic personal neoantigen vaccine for patients with melanoma. Nature. 2017;547: 217-21.

50. Sahin U, Derhovanessian E, Miller M, Kloke BP, Simon P, Lower M, et al. Personalized RNA mutanome vaccines mobilize poly-specific therapeutic immunity against cancer. Nature. 2017;547:222-6.

51. Yadav M, Jhunjhunwala S, Phung QT, Lupardus P, Tanguay J, Bumbaca S, et al. Predicting immunogenic tumour mutations by combining mass spectrometry and exome sequencing. Nature. 2014;515:572-6.

52. Warren RL, Choe G, Freeman DJ, Castellarin M, Munro S, Moore R, et al. Derivation of HLA types from shotgun sequence datasets. Genome Med. 2012;4:95.

53. McLaren W, Gil L, Hunt SE, Riat HS, Ritchie GR, Thormann A, et al. The Ensembl variant effect predictor. Genome Biol. 2016;17:122.

54. Andreatta M, Nielsen M. Gapped sequence alignment using artificial neural networks: application to the MHC class I system. Bioinformatics. 2016;32: 511-7.

55. Kent WJ, Sugnet CW, Furey TS, Roskin KM, Pringle TH, Zahler AM, et al. The human genome browser at UCSC. Genome Res. 2002;12:996-1006.

56. Bais $\mathrm{P}$, Namburi S, Gatti DM, Zhang X, Chuang JH. CloudNeo: a cloud pipeline for identifying patient-specific tumor neoantigens. Bioinformatics. 2017;33:3110-2.

57. Szolek A, Schubert B, Mohr C, Sturm M, Feldhahn M, Kohlbacher O. OptiType: precision HLA typing from next-generation sequencing data. Bioinformatics. 2014;30:3310-6.

58. Liu C, Yang X, Duffy B, Mohanakumar T, Mitra RD, Zody MC, et al. ATHLATES: accurate typing of human leukocyte antigen through exome sequencing. Nucleic Acids Res. 2013:41:e142

59. Hundal J, Carreno BM, Petti AA, Linette GP, Griffith OL, Mardis ER, et al PVAC-Seq: a genome-guided in silico approach to identifying tumor neoantigens. Genome Med. 2016;8:11.

60. Bjerregaard AM, Nielsen M, Hadrup SR, Szallasi Z, Eklund AC. MuPeXI: prediction of neo-epitopes from tumor sequencing data. Cancer Immunol Immunother. 2017;66:1123-30.

61. Saunders CT, Wong WS, Swamy S, Becq J, Murray LJ, Cheetham RK. Strelka: accurate somatic small-variant calling from sequenced tumor-normal sample pairs. Bioinformatics. 2012;28:1811-7.

62. Kim S, Scheffler K, Halpern AL, Bekritsky MA, Noh E, Kallberg M, et al. Strelka2: fast and accurate calling of germline and somatic variants. Nat Methods. 2018;15:591-4

63. Koboldt DC, Zhang Q, Larson DE, Shen D, McLellan MD, Lin L, et al. VarScan 2: somatic mutation and copy number alteration discovery in cancer by exome sequencing. Genome Res. 2012;22:568-76.

64. Fang LT, Afshar PT, Chhibber A, Mohiyuddin M, Fan Y, Mu JC, et al. An ensemble approach to accurately detect somatic mutations using SomaticSeq. Genome Biol. 2015;16:197.

65. Kim Y, Sidney J, Pinilla C, Sette A, Peters B. Derivation of an amino acid similarity matrix for peptide: $\mathrm{MHC}$ binding and its application as a Bayesian prior. BMC Bioinformatics. 2009;10:394

66. Schenck RO, Lakatos E, Gatenbee C, Graham TA, Anderson ARA. NeoPredPipe: high-throughput neoantigen prediction and recognition potential pipeline. BMC Bioinformatics. 2019;20:264.

67. Nielsen M, Lund O, Buus S, Lundegaard C. MHC class II epitope predictive algorithms. Immunology. 2010;130:319-28,

68. Butterfield LH. Cancer vaccines. BMJ. 2015;350:h988.
69. Zahm CD, Colluru VT, McNeel DG. Vaccination with high-affinity epitopes impairs antitumor efficacy by increasing PD-1 expression on CD8(+) T cells. Cancer Immunol Res. 2017;5:630-41.

70. Mahdavi M, Moreau V, Kheirollahi M. Identification of B and T cell epitope based peptide vaccine from IGF-1 receptor in breast cancer. J Mol Graph Model. 2017;75:316-21.

71. Blum JS, Wearsch PA, Cresswell P. Pathways of antigen processing. Annu Rev Immunol. 2013;31:443-73.

72. Coley WB. The treatment of malignant tumors by repeated inoculations of erysipelas. With a report of ten original cases. 1893. Clin Orthop Relat Res. 1991:(262):3-11.

73. Kugler A, Stuhler G, Walden P, Zoller G, Zobywalski A, Brossart P, et al. Regression of human metastatic renal cell carcinoma after vaccination with tumor cell-dendritic cell hybrids. Nat Med. 2000;6:332-6.

74. Stone JD, Harris DT, Kranz DM. TCR affinity for p/MHC formed by tumor antigens that are self-proteins: impact on efficacy and toxicity. Curr Opin Immunol. 2015;33:16-22.

75. Martinez P, McGranahan N, Birkbak NJ, Gerlinger M, Swanton C. Computational optimisation of targeted DNA sequencing for cancer detection. Sci Rep. 2013;3:3309.

76. Schumacher T, Bunse L, Pusch S, Sahm F, Wiestler B, Quandt J, et al. A vaccine targeting mutant IDH1 induces antitumour immunity. Nature. 2014; 512:324-7.

77. Mo Y, Wang Y, Xiong F, Ge X, Li Z, Li X, et al. Proteomic analysis of the molecular mechanism of lovastatin inhibiting the growth of nasopharyngeal carcinoma cells. J Cancer. 2019;10:2342-9.

78. Mo Y, Wang $Y$, Zhang L, Yang L, Zhou M, Li X, et al. The role of Wnt signaling pathway in tumor metabolic reprogramming. J Cancer. 2019;10: 3789-97.

79. Zhang Y, Xia M, Jin K, Wang S, Wei H, Fan C, et al. Function of the c-met receptor tyrosine kinase in carcinogenesis and associated therapeutic opportunities. Mol Cancer. 2018;17:45.

80. Inoges S, Tejada S, de Cerio AL, Gallego Perez-Larraya J, Espinos J, Idoate MA, et al. A phase II trial of autologous dendritic cell vaccination and radiochemotherapy following fluorescence-guided surgery in newly diagnosed glioblastoma patients. J Transl Med. 2017;15:104

81. Lilleby W, Gaudernack G, Brunsvig PF, Vlatkovic L, Schulz M, Mills K, et al. Phase I/lla clinical trial of a novel hTERT peptide vaccine in men with metastatic hormone-naive prostate cancer. Cancer Immunol Immunother. 2017;66:891-901.

82. Obara W, Eto M, Mimata H, Kohri K, Mitsuhata N, Miura I, et al. A phase I/II study of cancer peptide vaccine S-288310 in patients with advanced urothelial carcinoma of the bladder. Ann Oncol. 2017;28:798-803.

83. Yamasaki S, Miura Y, Davydova J, Vickers SM, Yamamoto M. Intravenous genetic mesothelin vaccine based on human adenovirus 40 inhibits growth and metastasis of pancreatic cancer. Int J Cancer. 2013;133:88-97.

84. Filley AC, Dey M. Dendritic cell based vaccination strategy: an evolving paradigm. J Neuro-Oncol. 2017;133:223-35.

85. Small EJ, Lance RS, Gardner TA, Karsh LI, Fong L, McCoy C, et al. A randomized phase $\|$ trial of Sipuleucel-T with concurrent versus sequential Abiraterone acetate plus prednisone in metastatic castration-resistant prostate Cancer. Clin Cancer Res. 2015;21:3862-9.

86. Melero I, Gaudernack G, Gerritsen W, Huber C, Parmiani G, Scholl S, et al. Therapeutic vaccines for cancer: an overview of clinical trials. Nat Rev Clin Oncol. 2014;11:509-24.

87. Aleksic M, Liddy N, Molloy PE, Pumphrey N, Vuidepot A, Chang KM, et al. Different affinity windows for virus and cancer-specific T-cell receptors: implications for therapeutic strategies. Eur J Immunol. 2012;42:3174-9.

88. Xing Y, Hogquist KA. T-cell tolerance: central and peripheral. Cold Spring Harb Perspect Biol. 2012:4:a006957.

89. Sarma S, Guo Y, Guilloux Y, Lee C, Bai XF, Liu Y. Cytotoxic T Iymphocytes to an unmutated tumor rejection antigen P1A: normal development but restrained effector function in vivo. J Exp Med. 1999;189:811-20.

90. Kreiter S, Castle JC, Tureci O, Sahin U. Targeting the tumor mutanome for personalized vaccination therapy. Oncoimmunology. 2012;1:768-9.

91. Linnemann C, van Buuren MM, Bies L, Verdegaal EM, Schotte R, Calis JJ, et al. High-throughput epitope discovery reveals frequent recognition of neoantigens by CD4+ T cells in human melanoma. Nat Med. 2015;21:81-5.

92. Robbins PF, Lu YC, El-Gamil M, Li YF, Gross C, Gartner J, et al. Mining exomic sequencing data to identify mutated antigens recognized by adoptively transferred tumor-reactive T cells. Nat Med. 2013;19:747-52. 
93. Castle JC, Kreiter S, Diekmann J, Lower M, van de Roemer N, de Graaf J, et al. Exploiting the mutanome for tumor vaccination. Cancer Res. 2012;72: 1081-91.

94. Carreno BM, Magrini V, Becker-Hapak M, Kaabinejadian S, Hundal J, Petti AA, et al. Cancer immunotherapy. A dendritic cell vaccine increases the breadth and diversity of melanoma neoantigen-specific T cells. Science. 2015;348:803-8.

95. Kreiter S, Selmi A, Diken M, Koslowski M, Britten CM, Huber C, et al. Intranodal vaccination with naked antigen-encoding RNA elicits potent prophylactic and therapeutic antitumoral immunity. Cancer Res. 2010;70: $9031-40$.

96. Hilf N, Kuttruff-Coqui S, Frenzel K, Bukur V, Stevanovic S, Gouttefangeas C, et al. Actively personalized vaccination trial for newly diagnosed glioblastoma. Nature. 2019:565:240-5.

97. Keskin DB, Anandappa AJ, Sun J, Tirosh I, Mathewson ND, Li S, et al. Neoantigen vaccine generates intratumoral $T$ cell responses in phase lb glioblastoma trial. Nature. 2019;565:234-9.

98. Hanna MG Jr, Hoover HC Jr, Vermorken JB, Harris JE, Pinedo HM. Adjuvant active specific immunotherapy of stage II and stage III colon cancer with an autologous tumor cell vaccine: first randomized phase III trials show promise. Vaccine. 2001;19:2576-82.

99. Deng X, Xiong F, Li X, Xiang B, Li Z, Wu X, et al. Application of atomic force microscopy in cancer research. J Nanobiotechnol. 2018;16:102.

100. Fan CM, Wang JP, Tang YY, Zhao J, He SY, Xiong F, et al. circMAN1A2 could serve as a novel serum biomarker for malignant tumors. Cancer Sci. 2019; 110:2180-8

101. Jin K, Wang S, Zhang Y, Xia M, Mo Y, Li X, et al. Long non-coding RNA PVT1 interacts with MYC and its downstream molecules to synergistically promote tumorigenesis. Cell Mol Life Sci. 2019;15:1-5.

102. Tang $Y$, He $Y$, Z Zhang $P$, Wang J, Fan C, Yang L, et al. LncRNAs regulate the cytoskeleton and related rho/ROCK signaling in cancer metastasis. Mol Cancer. 2018;17:77.

103. Wang M, Zhao J, Zhang L, Wei F, Lian Y, Wu Y, et al. Role of tumor microenvironment in tumorigenesis. J Cancer. 2017:8:761-73.

104. Wei F, Wu Y, Tang L, He Y, Shi L, Xiong F, et al. BPIFB1 (LPLUNC1) inhibits migration and invasion of nasopharyngeal carcinoma by interacting with VTN and VIM. Br J Cancer. 2018;118:233-47.

105. Wu Y, Wei F, Tang L, Liao Q, Wang H, Shi L, et al. Herpesvirus acts with the cytoskeleton and promotes cancer progression. J Cancer. 2019;10:2185-93.

106. Xia M, Zhang Y, Jin K, Lu Z, Zeng Z, Xiong W. Communication between mitochondria and other organelles: a brand-new perspective on mitochondria in cancer. Cell Biosci. 2019;9:27.

107. Jiang $X$, Wang J, Deng $X$, Xiong F, Ge J, Xiang B, et al. Role of the tumor microenvironment in PD-L1/PD-1-mediated tumor immune escape. Mol Cancer. 2019;18:10

108. Dong H, Strome SE, Salomao DR, Tamura H, Hirano F, Flies DB, et al. Tumorassociated B7-H1 promotes T-cell apoptosis: a potential mechanism of immune evasion. Nat Med. 2002;8:793-800.

109. Spranger S, Spaapen RM, Zha Y, Williams J, Meng Y, Ha TT, et al. Upregulation of $\mathrm{PD}-\mathrm{L} 1, \mathrm{IDO}$, and $\mathrm{T}$ (regs) in the melanoma tumor microenvironment is driven by CD8(+) T cells. Sci Transl Med. 2013;5: 200ra116.

110. Taube JM, Anders RA, Young GD, Xu H, Sharma R, McMiller TL, et al. Colocalization of inflammatory response with B7-h1 expression in human melanocytic lesions supports an adaptive resistance mechanism of immune escape. Sci Transl Med. 2012;4:127ra37.

111. Chen L, Han X. Anti-PD-1/PD-L1 therapy of human cancer: past, present, and future. J Clin Invest. 2015;125:3384-91.

112. Rekoske BT, Smith HA, Olson BM, Maricque BB, McNeel DG. PD-1 or PD-L1 blockade restores antitumor efficacy following SSX2 epitope-modified DNA vaccine immunization. Cancer Immunol Res. 2015;3:946-55

113. Soares KC, Rucki AA, Wu AA, Olino K, Xiao Q, Chai Y, et al. PD-1/PD-L1 blockade together with vaccine therapy facilitates effector T-cell infiltration into pancreatic tumors. J Immunother. 2015;38:1

114. Pardoll DM. The blockade of immune checkpoints in cancer immunotherapy. Nat Rev Cancer. 2012;12:252-64.

115. Hodi FS, O'Day SJ, McDermott DF, Weber RW, Sosman JA, Haanen JB, et al. Improved survival with ipilimumab in patients with metastatic melanoma. N Engl J Med. 2010;363:711-23.

116. Topalian SL, Hodi FS, Brahmer JR, Gettinger SN, Smith DC, McDermott DF, et al. Safety, activity, and immune correlates of anti-PD-1 antibody in cancer. N Engl J Med. 2012;366:2443-54.
117. Brahmer JR, Tykodi SS, Chow LQ, Hwu WJ, Topalian SL, Hwu P, et al. Safety and activity of anti-PD-L1 antibody in patients with advanced cancer. N Engl J Med. 2012;366:2455-65.

118. Wolchok JD, Kluger H, Callahan MK, Postow MA, Rizvi NA, Lesokhin AM, et al. Nivolumab plus ipilimumab in advanced melanoma. N Engl J Med. 2013; 369:122-33.

119. Le DT, Durham JN, Smith KN, Wang H, Bartlett BR, Aulakh LK, et al. Mismatch repair deficiency predicts response of solid tumors to PD-1 blockade. Science. 2017;357:409-13.

120. Naidoo J, Page DB, Li BT, Connell LC, Schindler K, Lacouture ME, et al. Toxicities of the anti-PD-1 and anti-PD-L1 immune checkpoint antibodies. Ann Oncol. 2015;26:2375-91.

121. Smyth MJ, Ngiow SF, Ribas A, Teng MW. Combination cancer immunotherapies tailored to the tumour microenvironment. Nat Rev Clin Oncol. 2016:13:143-58.

122. Ali OA, Lewin SA, Dranoff G, Mooney DJ. Vaccines combined with immune checkpoint antibodies promote cytotoxic T-cell activity and tumor eradication. Cancer Immunol Res. 2016;4:95-100.

123. Karyampudi L, Lamichhane P, Scheid AD, Kalli KR, Shreeder B, Krempski JW, et al. Accumulation of memory precursor CD8 T cells in regressing tumors following combination therapy with vaccine and anti-PD-1 antibody. Cancer Res. 2014;74:2974-85.

124. Curran MA, Montalvo W, Yagita H, Allison JP. PD-1 and CTLA-4 combination blockade expands infiltrating $T$ cells and reduces regulatory $T$ and myeloid cells within B16 melanoma tumors. Proc Natl Acad Sci U S A. 2010;107: 4275-80.

125. Leisegang M, Engels B, Schreiber K, Yew PY, Kiyotani K, Idel C, et al. Eradication of large solid tumors by gene therapy with a T-cell receptor targeting a single Cancer-specific point mutation. Clin Cancer Res. 2016;22: 2734-43.

126. Liu Y. Neoantigen: a Long march toward Cancer immunotherapy. Clin Cancer Res. 2016:22:2602-4.

127. Tran E, Turcotte S, Gros A, Robbins PF, Lu YC, Dudley ME, et al. Cancer immunotherapy based on mutation-specific CD4+ T cells in a patient with epithelial cancer. Science. 2014;344:641-5.

128. Liu S, Matsuzaki J, Wei L, Tsuji T, Battaglia S, Hu Q, et al. Efficient identification of neoantigen-specific T-cell responses in advanced human ovarian cancer. J Immunother Cancer. 2019;7:156.

129. Ma L, Dichwalkar T, Chang JYH, Cossette B, Garafola D, Zhang AQ, et al. Enhanced CAR-T cell activity against solid tumors by vaccine boosting through the chimeric receptor. Science. 2019;365:162-8.

130. Bakdash G, Buschow SI, Gorris MA, Halilovic A, Hato SV, Skold AE, et al. Expansion of a BDCA1+CD14+ myeloid cell population in melanoma patients may attenuate the efficacy of dendritic cell vaccines. Cancer Res. 2016:76:4332-46.

131. Klages K, Mayer CT, Lahl K, Loddenkemper C, Teng MW, Ngiow SF, et al. Selective depletion of Foxp3+ regulatory T cells improves effective therapeutic vaccination against established melanoma. Cancer Res. 2010;70: 7788-99.

132. Casares N, Rudilla F, Arribillaga L, Llopiz D, Riezu-Boj Jl, Lozano T, et al. A peptide inhibitor of FOXP3 impairs regulatory $T$ cell activity and improves vaccine efficacy in mice. J Immunol. 2010;185:5150-9.

133. Lozano T, Gorraiz M, Lasarte-Cia A, Ruiz M, Rabal O, Oyarzabal J, et al. Blockage of FOXP3 transcription factor dimerization and FOXP3/AML1 interaction inhibits $T$ regulatory cell activity: sequence optimization of a peptide inhibitor. Oncotarget. 2017:8:71709-24.

134. Eil R, Vodnala SK, Clever D, Klebanoff CA, Sukumar M, Pan JH, et al. Ionic immune suppression within the tumour microenvironment limits $T$ cell effector function. Nature. 2016;537:539-43.

135. Zhang B, Bowerman NA, Salama JK, Schmidt H, Spiotto MT, Schietinger A, et al. Induced sensitization of tumor stroma leads to eradication of established cancer by T cells. J Exp Med. 2007;204:49-55.

136. Lugade AA, Moran JP, Gerber SA, Rose RC, Frelinger JG, Lord EM. Local radiation therapy of B16 melanoma tumors increases the generation of tumor antigen-specific effector cells that traffic to the tumor. J Immunol. 2005:174:7516-23.

137. Greenberg PD, Cheever MA. Treatment of disseminated leukemia with cyclophosphamide and immune cells: tumor immunity reflects long-term persistence of tumor-specific donor T cells. J Immunol. 1984;133:3401-7.

138. Proietti E, Greco G, Garrone B, Baccarini S, Mauri C, Venditti M, et al. Importance of cyclophosphamide-induced bystander effect on T cells for a 
successful tumor eradication in response to adoptive immunotherapy in mice. J Clin Invest. 1998;101:429-41.

139. Manthey CL, Perera PY, Salkowski CA, Vogel SN. Taxol provides a second signal for murine macrophage tumoricidal activity. J Immunol. 1994;152: $825-31$

140. Berd D, Maguire HC Jr, Mastrangelo MJ. Induction of cell-mediated immunity to autologous melanoma cells and regression of metastases after treatment with a melanoma cell vaccine preceded by cyclophosphamide. Cancer Res. 1986;46:2572-7.

141. Nigam A, Yacavone RF, Zahurak ML, Johns CM, Pardoll DM, Piantadosi S, et al. Immunomodulatory properties of antineoplastic drugs administered in conjunction with GM-CSF-secreting cancer cell vaccines. Int J Oncol. 1998; 12:161-70.

142. Machiels JP, Reilly RT, Emens LA, Ercolini AM, Lei RY, Weintraub D, et al. Cyclophosphamide, doxorubicin, and paclitaxel enhance the antitumor immune response of granulocyte/macrophage-colony stimulating factorsecreting whole-cell vaccines in HER-2/neu tolerized mice. Cancer Res. 2001; 61:3689-97.

143. Ye Z, Li Z, Jin H, Qian Q. Therapeutic Cancer vaccines. Adv Exp Med Biol. 2016;909:139-67.

144. Anagnostou VK, Brahmer JR. Cancer immunotherapy: a future paradigm shift in the treatment of non-small cell lung cancer. Clin Cancer Res. 2015;21:976-84.

145. Melief CJ, van Hall T, Arens R, Ossendorp F, van der Burg SH. Therapeutic cancer vaccines. J Clin Invest. 2015;125:3401-12.

146. de Bruin EC, McGranahan N, Mitter R, Salm M, Wedge DC, Yates L, et al. Spatial and temporal diversity in genomic instability processes defines lung cancer evolution. Science. 2014;346:251-6.

147. Gerlinger M, Horswell S, Larkin J, Rowan AJ, Salm MP, Varela I, et al. Genomic architecture and evolution of clear cell renal cell carcinomas defined by multiregion sequencing. Nat Genet. 2014;46:225-33.

148. McGranahan N, Favero F, de Bruin EC, Birkbak NJ, Szallasi Z, Swanton C. Clonal status of actionable driver events and the timing of mutational processes in cancer evolution. Sci Transl Med. 2015;7:283ra54.

149. Rooney MS, Shukla SA, Wu CJ, Getz G, Hacohen N. Molecular and genetic properties of tumors associated with local immune cytolytic activity. Cell. 2015:160:48-61.

150. Kristensen VN. The antigenicity of the tumor cell - context matters. N Engl J Med. 2017:376:491-3.

151. Dai W, Zheng H, Cheung AK, Lung ML. Genetic and epigenetic landscape of nasopharyngeal carcinoma. Chin Clin Oncol. 2016;5:16.

152. Ali SM, Yao M, Yao J, Wang J, Cheng Y, Schrock AB, et al. Comprehensive genomic profiling of different subtypes of nasopharyngeal carcinoma reveals similarities and differences to guide targeted therapy. Cancer. 2017; 123:3628-37.

153. Zamora AE, Crawford JC, Allen EK, Guo XJ, Bakke J, Carter RA, et al. Pediatric patients with acute lymphoblastic leukemia generate abundant and functional neoantigen-specific CD8(+) T cell responses. Sci Transl Med. 2019: 11:eaat8549.

154. Parkhurst MR, Robbins PF, Tran E, Prickett TD, Gartner JJ, Jia L, et al. Unique Neoantigens Arise from Somatic Mutations in Patients with Gastrointestinal Cancers. Cancer Discov. 2019;9(8):1022-35.

155. Tran E, Robbins PF, Rosenberg SA. 'Final common pathway' of human cancer immunotherapy: targeting random somatic mutations. Nat Immunol. 2017;18:255-62.

156. Forbes SA, Beare D, Gunasekaran P, Leung K, Bindal N, Boutselakis H, et al. COSMIC: exploring the world's knowledge of somatic mutations in human cancer. Nucleic Acids Res. 2015;43:D805-11.

157. Laumont CM, Vincent K, Hesnard L, Audemard É, Bonneil É, Laverdure J-P, et al. Noncoding regions are the main source of targetable tumor-specific antigens. Sci Transl Med. 2018;10:eaau5516.

158. Gee MH, Han A, Lofgren SM, Beausang JF, Mendoza JL, Birnbaum ME, et al. Antigen identification for orphan $T$ cell receptors expressed on tumorinfiltrating lymphocytes. Cell. 2018;172:549-63 e16.

159. Probst P, Kopp J, Oxenius A, Colombo MP, Ritz D, Fugmann T, et al. Sarcoma eradication by doxorubicin and targeted TNF relies upon CD8(+) T-cell recognition of a retroviral antigen. Cancer Res. 2017;77:3644-54.

160. Tran E, Robbins PF, Lu YC, Prickett TD, Gartner JJ, Jia L, et al. T-cell transfer therapy targeting mutant KRAS in Cancer. N Engl J Med. 2016;375:2255-62.

161. Fan C, Tang Y, Wang J, Xiong F, Guo C, Wang Y, et al. Role of long noncoding RNAs in glucose metabolism in cancer. Mol Cancer. 2017;16:130.
162. Ali M, Foldvari Z, Giannakopoulou E, Boschen ML, Stronen E, Yang W, et al. Induction of neoantigen-reactive T cells from healthy donors. Nat Protoc. 2019;14:1926-43.

163. Caron E, Aebersold R, Banaei-Esfahani A, Chong C, Bassani-Sternberg M. A case for a human Immuno-Peptidome project consortium. Immunity. 2017;47:203-8.

\section{Publisher's Note}

Springer Nature remains neutral with regard to jurisdictional claims in published maps and institutional affiliations.
Ready to submit your research? Choose BMC and benefit from:

- fast, convenient online submission

- thorough peer review by experienced researchers in your field

- rapid publication on acceptance

- support for research data, including large and complex data types

- gold Open Access which fosters wider collaboration and increased citations

- maximum visibility for your research: over $100 \mathrm{M}$ website views per year

At BMC, research is always in progress.

Learn more biomedcentral.com/submissions 